\title{
DUKUNGAN SUAMI DAN DEPRESI PASCA MELAHIRKAN
}

\author{
Rustian Adi Sumantri ${ }^{1}$, Kondang Budiyani ${ }^{2}$ \\ ${ }^{12}$ Universitas Mercu Buana Yogyakarta \\ ${ }^{2}$ kondangpsi@yahoo.co.id
}

\begin{abstract}
Abstrak
Penelitian ini bertujuan untuk mengetahui hubungan antara dukungan suami dengan depresi pasca melahirkan pada wanita. Dalam penelitian ini dirumuskan suatu hipotesis yaitu ada hubungan negatif antara dukungan suami dengan depresi pasca melahirkan pada wanita. Subjek penelitian ini adalah wanita pasca melahirkan yang berada pada rentang usia dewasa awal yang bertempat tinggal di kabupaten Purworejo. Jumlah subjek dalam penelitian ini 50 orang. Alat pengumpul data yang digunakan dalam penelitian ini adalah Skala Dukungan Sosial dan BDI. Analisis data yang digunakan dalam penelitian ini dalah analisis product moment dari Pearson dengan hasil korelasi (Ray) sebesar -0,842 ( $\mathrm{p}<0,01)$. Berdasarkan hasil analisis data, hipotesis penelitian ini dapat diterima.
\end{abstract}

Kata kunci : depresi pasca melahirkan, dukungan suami

\section{HUSBAND SUPPORT AND POSTPARTUM DEPRESSION}

\author{
Rustian Adi Sumantri ${ }^{1}$, Kondang Budiyani ${ }^{2}$ \\ ${ }^{12}$ Universitas Mercu Buana Yogyakarta \\ ${ }^{2}$ kondangpsi@yahoo.co.id
}

\begin{abstract}
This study aims to determine the relationship between a husband's support and postpartum depression in women. In this study, the hypothesis proposed is that there is a negative relationship between a husband's support and postpartum depression in women. The subjects of this study were postpartum women who were in the early adult age range who lived in Purworejo district. The number of subjects in this study was 50 people. The data collection tool used in this study is the Scale of Social Support and BDI. The data were analyzed using product moment analysis from Pearson with the results of the correlation (Ray) of $-0.842(p<0.01)$. Based on the results of data analysis, the research hypothesis is acceptable.
\end{abstract}

Keywords: postpartum depression, husband's support

\section{PENDAHULUAN}

Manusia sebagai makhluk hidup memiliki naluri berkembang biak sebagai salah satu upaya untuk melestarikan jenisnya. Dalam hal mendapatkan keturunan atau anak secara alami dibutuhkan sepasang manusia yaitu pria dan wanita agar terjadi proses pembuahan. Pembuahan merupakan bertemunya sel sperma laki laki dengan sel ovum perempuan dalam rahim. Sel sperma yang bergabung dengan sel ovum yang menempel di dinding rahim seorang wanita akan tumbuh dan berkembang dari waktu ke waktu hingga akhirnya menjadi bayi selama kurang lebih 9 bulan 10 hari. Proses inilah yang disebut dengan hamil (Uddin, 2002).

Kelahiran merupakan titik puncak dari proses kehamilan. Hadirnya seorang bayi diharapkan dapat memberikan keadaan baru yang lebih baik bagi orang orang di 
sekitarnya (orang tua), apalagi bagi seorang wanita yang telah melahirkan akan merasakan kesempurnaan diri dalam melaksanakan fungsi keibuan sesuai dengan kodratnya sebagai wanita. Kelahiran bayi dapat memberikan perasaan bahagia, menambah kesempurnaan dalam rumah tangga, terlebih lagi jika bayi yang lahir sesuai dengan rencana dan harapan. Hal ini sesuai dengan pendapat Callister (2009) bahwa memiliki bayi merupakan keadaan yang menyenangkan dan seorang ibu yang baru saja melahirkan bayi akan merasa bahagia dan bersyukur.

Hal berbeda dikemukakan oleh Cox \& Ferguson (dalam Oktavia \& Basri, 2002). Menurutnya, periode setelah melahirkan selain memberikan dampak positif dapat pula menimbulkan stres. Stress yang dialami wanita setelah melahirkan biasanya berkaitan dengan masalah penyesuaian diri baik secara fisik maupun psikologis. Oleh karena stress dapat mempengaruhi keadaan emosi seseorang, maka wanita pasca melahirkan rentan terhadap berbagai gangguan emosional. Gangguan emosional tersebut dapat berupa munculnya emosi-emosi negatif, seperti mudah marah, sedih dan sensitif.

Menurut Sylvia (1998) baby blues merupakan gangguan yang dialami dua per tiga dari ibu melahirkan. Sementara postpartum psychosis merupakan gangguan yang jarang terjadi, kejadianya dua dari seribu ibu yang melahirkan. Postpartum depression atau depressi pasca melahirkan menempati urutan kedua yang sering dijumpai dari ketiga kemungkinan yang ada pada wanita pasca melahirkan. Namun demikian, depresi inilah yang membawa akibat paling nyata dalam kehidupan sehari-hari pada wanita setelah melahirkan. Screening dan penanganan dini sangat penting mengingat depresi ini merupakan jembatan penghubung antara jenis depresi yang paling ringan sampai jenis depresi yang paling berat yang membahayakan baik terhadap wanita pasca melahirkan maupun bayi yang dilahirkan.

Suryati (2008) menjelaskan depresi pasca melahirkan adalah suatu masa terganggunya fungsi psikologis ibu setelah melahirkan, yang berkaitan dengan perasaan sedih yang berlebihan dan diikuti dengan gejala penyertanya termasuk perubahan pola tidur dan nafsu makan, psikomotor, konsentrasi, rasa putus asa, tak berdaya. Callister (2009) menambahkan bahwa depresi pasca melahirkan ialah gangguan yang bermula dari reaksi biologis dalam tubuh ibu setelah melakukan persalinan. Calister meyakini bahwa perubahan hormon yang terjadi setelah seorang ibu melahirkan dapat mempengaruhi perubahan pada reaksi kimia di otak ditambah lagi dengan kelelahan dan stress yang menyertai proses kelahiran.

Beck (1985) mendefinisikan depresi dari adanya tanda-tanda sebagai berikut: (1) perubahan suasana hati yang spesifik, seperti kesedihan, kesepian; (2) konsep diri negatif disertai dengan kecenderungan untuk menyalahkan dan mencela diri; (3) keinginan untuk menghukum diri sendiri, tergantung kepada orang lain, menghindar, atau keinginan untuk mati; (4) perubahanperubahan dalam fisiologis seperti tubuh turun berat badan, sulit tidur, dan kehilangan nafsu 
makan; (5) perubahan dalam tingkat aktivitas seperti gerak melambat, perkembangan mental melambat atau sebaliknya dorongan aktivitas motorik menjadi cepat.

Terdapat beberapa akibat negatif dari munculnya depresi pasca melahirkan. Clark, Tluczek, \& Wenzel (2003) menyebutkan dampak dari adanya depresi pasca melahirkan yang dialami oleh bayi yang dilahirkan antara lain pola pengasuhan yang buruk, gangguan perilaku bayi, penundaan perkembangan kognitif, serta mendapatkan kekerasan fisik. Wanita yang mengalami depresi pasca melahirkan akan sering menunjukan ekspresi negatif kepada bayinya seperti sedih, tidak bersemangat, malas. Selain itu dapat pula wanita akan memunculkan sifat yang mudah marah, kecemasan bahkan tindakan yang melukai fisik.

Pasangan (suami) juga dapat pula mengalami akibat negatif dari munculnya depresi pasca melahirkan yang dialami istri. Hasil penelitian Meighan (dalam Clark, dkk, 2003) terhadap 8 pasangan suami istri yang wanitanya mengalami depresi pasca melahirkan menunjukkan bahwa suami merasakan kecemasan terhadap kesejahteraan istri, merasa bingung dengan perilaku istri, dan frustasi karena sikap istri yang buruk. Subjek penelitian (suami-suami) juga menunjukkan perubahan perilaku yang signifikan dalam hidupnya untuk mengakomodasi kebutuhan istri dan anaknya. Suami dilaporkan mengalami tingkat stres yang tinggi dalam hubungan perkawinan dan rumah tangga.

Faktor penyebab depresi pasca melahirkan cederung kompleks. Menurut
Knudson-Martin \& Silverstein (2009) penyebab depresi pasca melahirkan masih belum jelas. Menurutnya perubahan hormonal yang terjadi pasca melahirkan belum cukup untuk menjelaskan terjadinya depresi pasca melahirkan. Knudson-Martin \& Silverstein (2009) menemukan bahwa wanita setelah melahirkan akan mengalami perasaan gagal untuk menjadi "ibu yang baik" seperti yang sudah ditetapkan oleh kultur lingkunganya sehingga menjadikan para wanita pasca melahirkan menjadi depresi.

Dukungan sosial merupakan salah satu faktor yang sangat berpengaruh terhadap munculnya depresi pasca melahirkan dan bahkan dapat menurunkan angka peluang munculnya gangguan tersebut. Smet (1994) menjelaskan bahwa dukungan social ialah usaha untuk memberikan pertolongan kepada seseorang dengan tujuan untuk meningkatkan kualitas kesehatan mental, memberikan rasa percaya, nasihat, dorongan atau semangat dan penerimaan.

Dukungan sosial kepada wanita yang mengalami depresi pasca melahirkan dapat diberikan oleh orang-orang terdekat, seperti keluarga, sahabat, rekan kerja, dan terutama dari suami. Suami merupakan sumber yang paling utama dalam memberikan dukungan social kepada istrinya. Dukungan moral seorang suami merupakan hal yang sangat dibutuhkan karena suami adalah orang yang paling dekat dan bertanggung jawab atas kehamilan istrinya. Hal ini berdasarkan pernyataan Dagun (2002) bahwa dukungan seorang suami adalah hal yang memang dibutuhkan oleh istri baik saat hamil maupun 
ketika setelah melahirkan. Suami harus memberikan dukungan yang lebih besar kepada istrinya saat masa-masa tersebut.

Salah satu bentuk dukungan sosial yang dapat diberikan seorang suami kepada istrinya ialah dukungan emosional. Smet (1994) menjelaskan bahwa dukungan sosial dalam bentuk dukungan emosional mencakup ungkapan empati, kepedulian, perhatian, rasa kasih sayang. Dukungan emosional ini dapat memberikan efek ketenangan batin dan perasaan senang dalam diri istri dan akhrinya seorang istri menjadi lebih mudah meyesuaikan diri dalam mengasuh bayinya. Selain dukungan emosional, menurut Smet (1994) jenis dukungan sosial lain yang dapat diberikan ialah dukungan penghargaan, dukungan instrumental, dan dukungan informatif. Dukungan penghargaan terjadi lewat ungkapan hormat dan rasa penghargaan kepada seorang istri untuk meningkatkan penghargaan dirinya. Dukungan instrumen bersifat bantuan yang bersifat material. Dukungan informatif mencakup nasihat nasihat dan saran yang positif. Semua bentuk dukungan sosial tersebut sangat berarti bagi wanita terutama yang mengalami depresi pasca melahirkan.

Adanya dukungan suami akan memberikan kontribusi yang sangat berarti terhadap wanita pasca melahirkan dalam menghadapi stres yang muncul. Hal ini berdasarkan pendapat Johnson dan Johnson (dalam Matson, 2011) bahwa dukungan sosial akan meningkatkan kesejahteraan psikologis individu dan kemampuan pengelolaan stres dengan menyediakan pelayanan, perawatan, kasih sayang, sumbersumber informasi dan umpan balik yang dibutuhkan untuk menghadapi stres. Demikian juga Sunberg, Winebarger, Taplin (2007) yang menjelaskan bahwa dukungan sosial terutama dari orang terdekat istri yaitu suami bermanfaat untuk mempercepat kesembuhan dan mengurangi resiko komplikasi pada saat kehamilan maupun masalah lain setelah melahirkan seperti depresi pasca melahirkan pada wanita. Dengan demikian adanya dukungan suami akan memberikan kemampuan yang lebih kepada wanita dalam menghadapi stres yang yang muncul dan wanita tersebut dapat terhindar dari depresi pasca melahirkan.

Hipotesis yang diajukan peneliti adalah ada hubungan negatif antara dukungan sosial suami dengan depresi pasca melahirkan pada wanita setelah melahirkan. Semakin tinggi dukungan sosial suami yang diperoleh maka semakin rendah depresi pasca melahirkan pada wanita setelah melahirkan. Sebaliknya, semakin rendah dukungan sosial yang diperoleh maka semakin tinggi depresi pasca melahirkan yang dialami.

\section{METODE}

Subjek yang digunakan dalam penelitian ini adalah wanita pasca melahirkan dengan ciri-ciri : a) wanita termasuk dalam usia dewasa awal (21-40), b) telah melahirkan baik kelahiran pertama atau kelahirkan berikutnya, c) rentang usia bayi yaitu antara 14 hari hingga 1 tahun. Subjek merupakan anggota posyandu di kabupaten purworejo.

Alat pengumpul data adalah skala 
dukungan suami dengan koefisien validitas sebesar dan skala Beck Depression Inventory dengan koefisien validitas sebesar 0,2338 0,6097 dan koefisien reliabilitas sebesar 0,833 Sedangkan skala dukungan suami memiliki koefisien validitas $0,431-0,819$. Koefisien reliabilitas sebesar 0,924 .

\section{HASIL DAN PEMBAHASAN}

Berdasarkan analisis korelasi product moment diperoleh koefisien korelasi sebesar $\left(r_{x y}\right)=-0,842$ dengan taraf signifikansi 0,000 $(\mathrm{p}<0,01)$. Hal ini menunjukan bahwa dukungan suami memiliki hubungan negatif yang signifikan terhadap depresi pasca melahirkan, artinya semakin tinggi dukungan suami, maka semakin rendah depresi pasca melahirkan yang terjadi pada wanita setelah melahirkan. Sebaliknya semakin rendah dukungan suami, maka semakin tinggi depresi pasca melahirkan yang terjadi. Hal tersebut menunjukan bahwa hipotesis yang diajukan dalam penelitian ini diterima.

Hasil penelitian ini sesuai dengan pendapat dari Marshall (2004) bahwa kurangnya dukungan sosial, terutama dukungan suami, dapat bersumber kepada tingginya depresi pada wanita setelah melahirkan. Dukungan suami yang kurang memadai akan menyebabkan wanita merasa kurang diperhatikan, tidak disayangi, tidak mendapatkan bantuan padahal pada masa setelah melahirkan merupakan proses penyesuaian yang berat bagi wanita karena memiliki tugas dan tanggung jawab baru terhadap bayi.

Weiss (1991) menjelaskan bahwa
Individu yang menerima dukungan sosial akan meningkatkan self esteem. Wanita pasca melahirkan yang mendapat dukungan suami yang tinggi akan memiliki self esteem yang tinggi pula sehingga merasa dirinya merasa percaya dan sanggup manghadapi berbagai stres yang muncul. Stres, menurut Sarafino (dalam Smet, 1994) digambarkan sebagai stimulus yaitu bahwa lingkungan dapat menjadi stresor terhadap individu. Segala keadaan yang tidak menyenangkan yang muncul baik sebelum melahirkan maupun setelah melahirkan dapat dianggap stressor bagi wanita pasca melahirkan. Hal tersebut berdasarkan pendapat Callister (2009) wanita pasca melahirkan banyak menghadapi stres dikarenakan beban baru yaitu bayi yang dilahirkan dengan berbagai tanggung jawab sebagai seorang ibu.

Beck (1985) menjelaskan bahwa gejalagejala depresi dapat dikenali melalui beberapa simtom yaitu emosional, kognitif, motivasional, fisik, dan vegetatif. Gejala gejala tersebut merupakan gejala depresi pasca melahirkan yang terjadi pada wanita setelah melakukan persalinan. Oleh karena itu dukungan suami merupakan faktor yang berkontribusi cukup besar untuk mengurangi kecenderungan depresi pasca melahirkan pada istri. Penjelasan tersebut diperkuat dengan hasil penelitian Ayu \& Lailatushifah (2009) yang menyatakan bahwa ada hubungan negatif antara dukungan suami dengan depresi pasca melahirkan. Semakin tinggi dukungan suami maka akan diikuti cenderung semakin randahnya tingkat depresi pasca melahirkan. Demikian juga dengan semakin 
rendahnya dukungan suami yang diberikan kepada istri setelah melahirkan maka depresi pasca melahirkan cenderung tinggi.

Adanya dukungan suami akan memberikan kontribusi terhadap wanita pasca melahirkan dalam menghadapi stress yang muncul. Hal ini berdasarkan pendapat Johnson \& Johnson (1991) bahwa dukungan sosial akan meningkatkan kesejahteraan psikologis individu dan kemampuan pengelolaan stres dengan menyediakan pelayanan, perawatan, kasih sayang, sumbersumber informasi dan umpan balik yang dibutuhkan untuk menghadapi stres. Demikian juga Sunberg, Winebarger, Taplin (2007) yang menjelaskan bahwa dukungan sosial terutama dari orang terdekat istri yaitu suami bermanfaat untuk mempercepat kesembuhan dan mengurangi resiko komplikasi pada saat kehamilan maupun masalah lain setelah melahirkan seperti depresi pasca melahirkan pada wanita.

Berdasarkan kategori skor subjek pada variabel dukungan suami diperoleh hasil bahwa sebanyak 43 subjek (86\%) berada pada kategori tinggi, 7 subjek (14\%) berada pada kategori sedang dan tidak ada subjek yang berada pada ketegori rendah. Data tersebut menunjukkan bahwa sebagian besar subjek memiliki tingkat dukungan suami yang tinggi. Hasil penelitian ini juga menunjukan bahwa sebagian besar subjek tidak mengalami depresi. Berdasarkan kategori skor subjek pada variabel depresi pasca melahirkan didapat bahwa sebanyak 24 subjek (48\%) tidak mengalami depresi, 14 subjek (28\%) mengalami depresi ringan, 8 subjek (16\%) mengalami deperesi sedang dan yang mengalami depresi berat ialah sebanyak 4 subjek (8\%). Hasil tersebut menandakan bahwa sebagian besar subjek memiliki depresi pasca melahirkan yang rendah.

Hasil penelitian ini menunjukkan bahwa wanita pasca melahirkan memiliki tingkat kecenderungan depresi pasca melahirkan yang rendah. Berdasarkan karakteristik subjek penelitian, sebagian besar subjek penelitian berada di lingkungan pedesaan yang sangat terasa kekeluargaanya antara tetangga yang satu dengan tetangga yang lain. Menurut peneliti, lingkungan pedesaan setempat juga ikut andil dalam memberikan dukungan sosial kepada subjek sehinga tanpa dukungan suami yang memadai pun subjek penelitian masih mendapatkan dukungan dari lingkungan sosialnya. Selain itu, urutan kelahiran juga memengaruhi munculnya depresi pasca melahirkan karena sebagian besar wanita pasca melahirkan dalam penelitian ini bukan merupakan kelahiran anak pertama. Hal ini sesuai dengan pendapat Pitt (1994) bahwa kecenderungan depresi pada kelahiran anak pertama akan lebih tinggi daripada kelahiran berikutnya.

Rentang waktu setelah melahirkan juga memengaruhi tinggi-rendahnya tingkat depresi yang muncul pada wanita pasca melahirkan. Seharusnya penelitian ini menetapkan usia kelahirkan subjek penelitian maksimal 6 bulan setelah melahirkan sesuai yang dikemukakan oleh Wisner dkk (2002) yaitu bahwa gejala depresi pasca melahirkan dapat bertahan hingga 6 bulan setelah melahirkan. Masa 6 bulan setelah melahirkan merupakan 
masa yang paling rentan pada wanita menanggung tanggung jawab mengasuh bayi.

Status subjek penelitian yang sebagai anggota posyandu juga memengaruh tinggi rendahnya kecenderungan depresi pasca melahirkan yang dialami subjek penelitian. Perkumpulan anggota posyandu merupakan komunitas dengan tujuan yang sama yaitu mensejahterakan ibu dan bayi anggota posyandu. Status anggota posyandu tersebut secara tidak langsung merupakan komunitas sosial yang saling memberikan dukungan sosial satu sama lain sehingga dapat menutupi kekurangan dukungan suami yang diterima. Selain itu, rata - rata anggota posyandu merupakan wanita yang telah mendapatkan penyuluhan kesehatan dari Dinas Kesehatan sehingga telah siap menghadapi kehamilan dan kelahiran dibanding wanita yang bukan anggota posyandu.

Pada penelitian ini sumbangan yang diberikan variabel dukungan suami terhadap depresi pasca melahirkan dapat dilihat pada koefisien determinasi $\left(\mathrm{R}^{2}\right)=0,710$ yang menunjukkan bahwa sumbangan variabel dukungan suami terhadap depresi psaca melahirkan sebesar $71 \%$, sedangkan sisanya sebesar 29\% dipengaruhi oleh variabel lain yang tidak termasuk dalam penelitian ini. Faktor lain yang mempengaruhi munculnya depresi pasca melahirkan pada wanita ialah faktor konstitusional yaitu depresi pasca melahirkan lebih sering terjadi pada wanita yang melahirkan pertama kali. Faktor hormon yaitu karena setelah melahirkan, wanita mengalami perubahan hormon - hormon antara lain hormon estrogen, progesterone, dan kortisol yang menurun drastis dalam 48 jam setelah kelahiran. Sebagian besar wanita dalam keadaan seperti ini memiliki resiko berkembangnya gejala-gejala depresi dikarenakan perubahan kadar hormon hormon tersebut. Faktor psikososial mencakup berbagai masalah antara diri wanita dengan lingkunganya seperti Wanita yang mengalami perselisihan dalam perkawinan, ketidak harmonisan rumah tangga, peristiwa traumatik seperti kematian anggota keluarga, kehilangan pekerjaan atau wanita yang bekerja lebih mungkin mengalami depresi pasca melahirkan. Riwayat medis, yakni wanita yang memliki riwayat depresi, riwayat keluarga yang mengalami depresi, atau mengalami depresi saat kehamilan meningkatkan resiko munculnya depresi pasca melahirkan. Terlebih lagi wanita yang pernah mengalami depresi pasca melahirkan pada persalinan sebelumnya. Riwayat tersebut berpotensi meningkatkan resiko munculnya depresi pasca melahirkan sebesar $90 \%$ pada kelahiran berikutnya.

Berdasarkan uraian di atas dapat disimpulkan bahwa dukungan suami menjadi salah satu faktor yang dapat mempengaruhi munculnya depresi pasca melahirkan pada wanita setelah melakukan persalinan. Semakin tinggi dukungan suami kepada istri, maka semakin rendah depresi pasca melahirkan yang terjadi. Sebaliknya semakin rendah dukungan suami, maka semakin tinggi depresi pasca melahirkan yang terjadi pada wanita setelah melakukan persalinan. 
KESIMPULAN

Tingginya dukungan suami mempengaruhi rendahnya depresi pasca melahirkan. Hal ini dibuktikan dengan adanya hubungan negatif sebesar $-0,842$ dantara dukungan suami dengna depresi pasca melahirkan. Hubungan negatif tersebut berarti bahwa semakin tinggi dukungan suami kepada istri setelah melahirkan maka akan semakin rendah depresi pasca melahirkan. Saran yang diajukan adalah :

\section{Bagi Suami}

Dukungan suami terbukti cukup berperan dalam mengurangi intensitas depresi pasca melahirkan yang dialami istri. Dukungan suami yang terdiri dari beberapa dimensi yaitu dukungan emosional, dukungan penghargaan, dukungan instrumen, dukungan informatif dapat berdampak pada kemampuan istri menghadapi berbagai stres setelah melahirkan. Sehingga dengan demikian para suami harus memberikan dukugan tidak hanya saat menjelang kelahirkan saja, namun berlanjut pada setelah kelahirkan anak untuk membantu wanita menghadapi tekanan yang muncul setelah kelahirkanBagi Subjek Penelitian (Wanita Pasca Melahirkan).

\section{Bagi Subjek Penelitian (Wanita Pasca} Melahirkan)

Banyak hal yang dapat dilakukan oleh wanita dalam mencegah munculnya depresi pasca melahirkan. Hal utama ialah selalu aktif mendapatkan dukungan suami. Hal tersebut dapat dilakukan lewar mempererat hubungan rumah tangga dengan suami, selalu terbuka terhadap pasangan tentang apa saja masalah yang dihadapi setelah melahirkan, mengembangkan pengetahuan tentang pengasuhan anak, dan juga meminta dukungan dari kerabat dan teman dekat

\section{Bagi Pihak-Pihak Terkait}

Pihak - pihak terkait yang dimaksud ialah keluarga, rekan kerja, tetangga, rumash sakit, dan posyandu. Pihak pihak tersebut merupakan komunitas di sekitar wanita yang dapat berpengaruh terhadap kecenderungan munculnya depresi pasca melahirkan. Hal- hal dapat dilakukan keluarga, rekan kerja dan tetangga ialah selalu memberikan dorongan untuk para wanita pasca melahirkan agar selalu mencari dukungan dari suaminya. Selain itu juga memberikan masukan kepada para suami agar selalu memberikan dukungan kepada istri baik ketika hamil maupun setelah melahirkan. Hal lain yang dapat dilakukan oleh posyandu dan rumah sakit yaitu selain memeriksa perkembangan dan pertumbuhan bayi ialah memberikan pengetahuan lewat seminar atau dengan cara yang lain yang bertujuan untuk menambah wawasan wanita-wanita yang baru melahirkan dalam merawat bayi sekaligus mengurus rumah tangga.

\section{Bagi Peneliti Selanjutnya}

Bagi peneliti selanjutnya disarankan untuk memperhitungkan variabel lain 
seperti usia setelah kelahiran, usia saat melahirkan, urutan kelahiran, lingkungan sosial, pekerjaan wanita, dan faktor - faktor lainya yang menjadi faktor depresi pasca melahirkan mengingat bahwa masih ada 29\% variabel lain yang mempengaruhi depresi pasca melahirkan.

\section{DAFTAR PUSTAKA}

American Psychiatric Association. (1994). Diagnostic and manual statistical of mental disorder, Fourth Edition (DSM IV). Washington, D.C: American Psychiatric Association.

Ayu, F., \& Lailatusifah, S. (2009). Dukungan suami dan depresi pasca melahirkan. Insight. 7 (1), $14-22$.

Azwar, S. (2001). Reliabilitas dan validitas. Yogyakarta: Pustaka Pelajar.

Azwar, S. (2003). Penyusunan skala psikologis. Yogyakarta: Pustaka Pelajar.

Beck, A. (1985). Depression causes and treatment. Pensylvania: Philadhelpia Press

Callister, L.C. (2009). Managing postpartum depression: A gospel perspective. Birmingham: Ensign.

Clark, R., Tluczek, A., \& Wenzel, A. (2003). Psychotherapy for postpartum depression: A preliminary report. American Journal of Orthopsychiatry, 73(4), 441-454.

Cohen, S.M., \& Syme, L. (1985). Social support and health. Philadelphia: W.B. Sounders Company.

Dagun, S.M. (2002). Psikologi keluarga. Jakarta: Rineka Cipta.

Goldberger, L., \& Breznitz, S. (1982). Handbook of stress: Theretical and clinical aspects. New York: The Free
Press.

Hadi, S. (2000). Analisis regresi. Yogyakarta: Andi Offset.

Hawari, D. (1997). Ilmu Kedokteran Jiwa Dan Kesehatan Jiwa. Yogyakarta: Bhakti Prima Jaya.

Hendrick, V., Altshuler, L., \& Suri, C. (1998). Course of mood and anxiety disorder during pregnancy and postpartum period. Journal of Clinical Psychiatry, 52(29), 256 - 293.

Inandi, T., Elci, O.C., \& Sahin, T. (2002). Risk faktor for depression in postnatal first year in eastern Turkey. International Journal Of Epidemiology, 31(3), 1201-1227.

Johnson, D.W., \& Johnson, F. P. (1991). Joining Together Group Theory And Group Skill. London: Prentice Hall Inc.

Joy, S. (2012). Postpartum depression. Emedicine Medscape Psychiatry, 25(21), 68-103.

Knudson-Martin, C., \& Silverstein, R. (2009). Suffering in silence: A qualitative metadata-analysis of postpartum depression. Journal of Marital and Family Therapy, 35(4), 145-158.

Kurtsjens, S., \& Wolke, D. (2001). Effect of maternal depression on cognitive development of children over the first 7 years of life. Child Psychology, 42(5), 623-636.

Marshall, F. (2004). Mengatasi Depresi Pasca Melahirkan. Jakarta: Arcan.

Maslim, R. (2002). Diagnosis Gangguan Jiwa. Jakarta: Tim Penyusun PPDGJ III

Matson, H. (2011). Linking Health Communication With Social Support. UK: Hunt Publishing Co.

Nazara Y. (2009). Efektivitas psikoedukasi terhadap pencegahan depresi pascasalin. Jurnal Keperawatan Poltekkes Medan. 
33. (4). 16 - 37

O'Hara M.W., \& Swain AM. ( 1996). Rates and risk of postpartum depression: A meta analysis. International Review Psychiatry, 8(4), 37-54.

Oktavia. L., \& Basri, AS. (2002). Hubungan antara dukungan sosial yang diterima secara nyata dengan ada/tidaknya gangguan depresi pasca sailin pada ibu dewasa muda. Jurnal Psikologi, 8(1), $15-22$.

Parry, B. L. (1995). Postpartum Psychiatric Syndromes. Comprehensive Text Book of Psychiatry. Editor: Kaplan, H. I \& Sadock, B. J. Baltimore: Wiliams \& Wilkins.

Pitt, B. (1994). Kehamilan Dan Persalinan: Menikmati Tugas Sebagai Ibu. Jakarta: Arcan.

Puthut, B.S. (2001). Dukungan suami dan stres pada ibu saat hamil. Skripsi. (Tidak diterbitkan). Yogyakarta: Universitas Mercu Buana Yogyakarta.

Retno Tri Wulandari. (2006). Citra raga dan derpesi pasca melahirkan. Skripsi (Tidak diterbitkan). Yogjakarta: Universitas Mercu Buana Yogyakarta.

Retnowati, S. (1990). Terapi kognitif dan terapi perilaki pada penanganan gangguan depresi. Tesis (Tidak Diterbitkan). Yogyakarta: Pasca Sarjana Fakultas Psikologi Universitas Gadjah Mada

Santrock, John W. 2002. Life Span Development. Jakarta: Erlangga.

Sarafino, E,P. (1990). Health Psychology: Biopsychological Interaction. Kanada: John Wiley \& Sons, Inc.

Sarason, I.G., Levine, H.M., Basham, R.B., \& Sarason, B.R. (1983). Asessing Social Support: The Social Support Questionanaire. Journal of Personality and Social Psychology, 44(1), 127-139.

Smet, B. (1994). Psikologi kesehatan. Jakarta:
Grasindo.

Sheereve, C. (1992). Mengenal dan Mengatasi Depresi. Jakarta: Arcan.

Sunberg, T.M., Winebarger, M., \& Taplin, J. (2007). Perceived Social Support and Mortality in Older People. The Journals of Gerontology: Psychological sciences \& social sciences, 61(4) 147-152.

Suryati. (2008). The baby blues and postnatal depression. Jurnal Kesehatan Masyarakat, 89(2), 15 - 19.

Sylvia, C. (1998). Kehidupan Seks Selama Kehamilan dan Melahirkan. Jakarta: Arcan.

Taylor, (2006). Health Psychology. New York: MC.Graw Hill Inc.

Tempo. (2012). Depresi, Bunuh Diri. Koran. Tempo Edisi Senin 19 November 2012. Jakarta: Tempo.

Uddin, J. Dr. (2002). Ilmu Kedokteran dan Kesehatan 1. Jakarta: Departemen Agama Republik Indoesia.

Weiner, Irving B. (2003). Handbook of Psychology Volume 9: Health Psychology. Florida: John Wiley \& Sons, inc.

Weiss, S.M. (1991). Perspective in Behavioral Medicine: Health and Work. New Jersey: Lawrence Erlbaum Associates.

Wisner, K.L., Parry, B.L., Pointek, \& Catherine, M. (2002). Postpartum Depression. The New England Journal Of Medicine, 34(3), 216 - 275. 